\title{
Navel ill in new born calves and its successful treatment
}

\author{
Ganga Naik S., Ananda K J, Kavitha Rani B., Kotresh A M, Shambulingappa B E, Patel S R \\ Veterinary college, Karnataka Veterinary and Fishery Science University, \\ vinobanagar, shimoga, karnataka 577204, India \\ * Corresponding author email : ganganaik2007@gmail.com \\ Published Online : 30-04-2011
}

\section{Introduction}

Navel ill is a condition in which the Navel portion of the calf is infected, by bacteria's contamination of umbilicus following parturition. The infection spreads via the umbilical cord. The umbilical cord is a connection between the fetus and mother, which provides necessary nutrient for the development of the fetus during intrauterine life.

Swellings of the umbilical stalk, with or without herniation, are common conditions in calves (Rings, 1995). The umbilical cord consists of the amniotic membrane, the umbilical veins, the umbilical arteries and the urachus. The amniotic membrane of the umbilical cord is torn at birth and gradually the umbilical vein and the urachus closes but they remain temporarily outside the umbilicus. The umbilical arteries retract as far back as the top of the bladder and it becomes round ligament of the urinary bladder. Normally umbilical cord dries up with in one week after the birth (Radostits et al, 2000).

The patent urachus is a common condition in calves which is frequently associated with omphalitis. A membranous urethral diaphragm prevent closure of the urachus in a female calf. The patent urachus was complicated by an ascending infection of the intraabdominal umbilical remnants. Following surgical removal of the urachus and umbilical vessels along with transsection of the membranous diaphragm the calf experienced an uncomplicated recovery. (Hunt and Allen, 1989).

The infection of the umbilicus and its associated structures occur commonly in the newborn calf. It may occur soon after the birth and may result in omphalitis, omphalophlebitis, omphaloarteritis or infection of the urachus. Umbilical infection usually occurs as a mixed bacterial infection. Localized infection may occur in joints, bones, meninges, eyes, endocardium and end arteries of the feet, ears and tail. The Navel infection, act as source of infection leading to septicemia in neonates due to failure of transfer of maternal immunity to the fetus.

Omphalitis is an inflammation of the umbilicus and it occurs 2-5 days after the birth. In omphalitis, umbilicus is enlarged, painful on palpation and may be closed or draining purulent material through a fistula. Omphalophlebitis is a condition in which there is inflammation of the umbilical vein. It may occur in distal part or extend from the umbilicus to the liver. Here abscesses may develop along the course of the vein and spread to liver. Omphaloarteritis is a condition in which the abscesses occur along the course of the umbilical arteries from the umbilicus to the internal iliac arteries. In omphalophlebitis and omphaloarteritis, the clinical findings are enlarged umbilicus with purulent material, chronic toxemia, unthriftiness. The urachitis is an infection of the urachus along its course i.e., from the umbilicus to the urinary bladder. (Radostits et al, 2000).

\section{History and observation}

About 10 calves with a history of swelling in the umbilical region were presented to the peripheral hospital, Shimoga. On clinical examination, 4 calves revealed swelling of the umbilical region, which was painful. About 6 calves had purulent discharge complicated with maggot wound, decrease in milk intake and dullness.

\section{Treatment and Discussion}

Closed abscesses were opened with B. P. Blade, the pus was drained and washed with the $1 \%$ potassium permanganate solution and smeared with tincture iodine solution. On second day again, the pus was drained and washed with $1 \%$ potassium permanganate solution and smeared with Gamma benzene hexachloride and proflavine hemisulphate with cetrimide cream (Virbac Animal Health India Pvt Ltd, Mumbai, India). 
The calves with the maggot wounds were washed with $1 \%$ potassium permanganate solution and packed with turpentine oil gauze in the umbilicus. On second day, the wound was cleaned with the hydrogen peroxide and smeared with Gamma benzene hexachloride and proflavine hemisulphate with cetrimide cream (Virbac Animal Health India Pvt Ltd, Mumbai).

The calves were treated with Strepto-Penicillin (Zydus Animal Heath Ltd, Ahmedabad) and Meloxicam (Intas Pharmaceuticals Ltd, Ahmedabad) injection, administered intramuscularly for 5 days. The routine dressing of wound with Hydrogen peroxide solution, Gamma benzene hexachloride and proflavine hemisulphate with cetrimide cream (Virbac Animal Health India Pvt Ltd, Mumbai) was carried out. The area surrounding the umbilicus was smeared with fly repellant ointment to prevent the infestation of the wound with maggot.

\section{References}

1. Radostits, O. M.,et. al. (2000). Veterinary Medicine. A Text book of the disease of cattle, sheep, pig , goat and horses. $9^{\text {th }}$ edn, W.B.Saunders, Philadelphia, pp 1442-1452.

2. Hunt, R. J and Allen, D. Jr. (1989). Treatment of patent urachus associated with a congenital imperforate urethra in a calf. Can.Vet.J.46(8):732-734.

3. Rings, D. M. (1995). Umbelical hernias, umbilical abscesses and urachal fistulas, surgical consideration. Vet Clin North Am Food Anim Pract. 11(1):137-148.

4. Vegad, J.L and Katiyan, A.K (1998). A Treatment of veterinary systemic pathology. Vikas Publishing House Pvt. Ltd. It Edn. 